\title{
Contact-induced change in Jaffa Palestinian Arabic: The case of (§)
}

\author{
Uri Horesh* $^{*}$
}

LSA Annual Meeting, Minneapolis, January 2-5, 2014

1. Introduction. One of the most salient features of Arabic is pharyngeality. It is prevalent in its phonemic inventory both in primary articulation - voiced $/ \mathrm{S} /$ - and voiceless $/ \mathrm{h} /$ - and in secondarily articulated phonemes known commonly as "emphatic" consonants.

As a result of the 1948 occupation of Palestine by Zionist forces, Jaffa, and much of the Arabic-speaking population of Palestine elsewhere, has transformed from a monolingual speech community into a bilingual one, having acquired Modern Hebrew as its L2. While many Palestinian towns and villages have remained segregated, Jaffa has become a "mixed town," in that Palestinians and Jewish Israelis have been living there side by side for the past 65 years. One of the linguistic consequences of this bilingual (or indeed multilingual) cohabitation is structural borrowing (cf. Thomason and Kaufman 1988). Of particular interest to this study are the variable lenition and/or deletion of the voiced pharyngeal fricative among native speakers of Arabic, who are also L2 speakers of Hebrew.

2. Methodology. In order to test the hypothesis that structural change, especially in the phonology of Jaffa Palestinian Arabic, has been under way as a result of contact with Hebrew, sociolinguistic interviews were carried out in both Jaffa itself and in the West Bank communities of Ramallah and Jerusalem. The latter two were used as a control group, as West Bank speakers nowadays are much less exposed to Hebrew than their Jaffa counterparts.

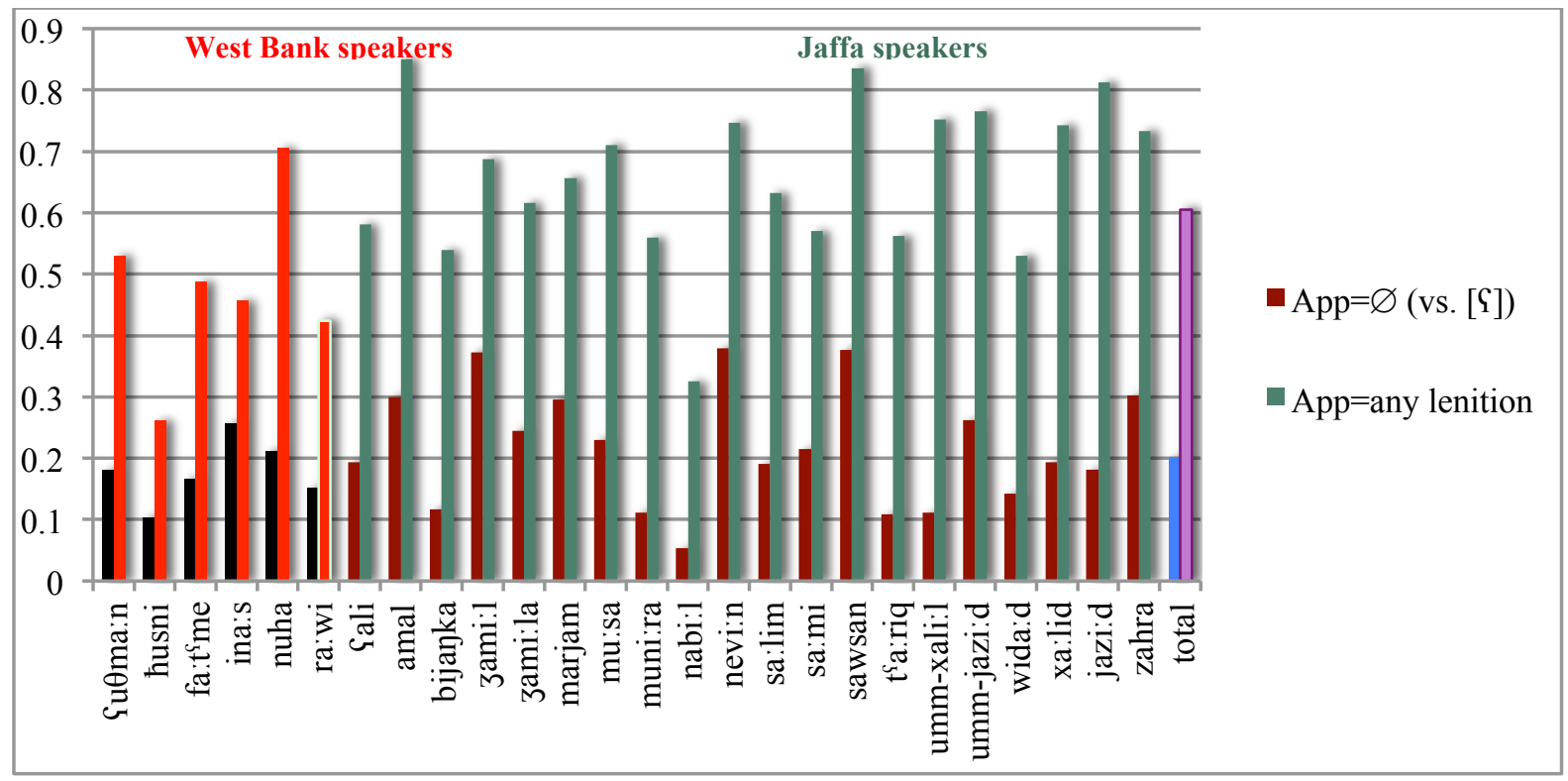

Figure 1. Cross-tabulation of (؟) by speaker, community and type of lenition

\footnotetext{
* The author would like to extend his utmost gratitude to Enam Al-Wer at the University of Essex for her guidance and support in completing this project.

Author: Uri Horesh, University of Essex and Northwestern University (uri.horesh@northwestern.edu).
} 
Since the structural change in question has more than one possible "application" in the variable rule paradigm, various quantitative models have been applied to assess the effect of contact on language variation and change in this instance. The bar graph in Figure 1 illustrates a simple cross-tabulation of speaker and the dependent variable across the two speech communities, with two different types of application: full deletion and any type of lenition of the pharyngeal. We see that both the high-contact Jaffa speech community and the low-contact West Bank community have garden varieties of lenition, but the Jaffa community, especially younger speakers, tend more to apply the full lenition rule. Figure $\mathbf{2}$ is a schematic chart indicating all of the statistical models that were run. In Section 4 below, only one table each from two representative models are shown. A full set of results is available in Horesh (2014).

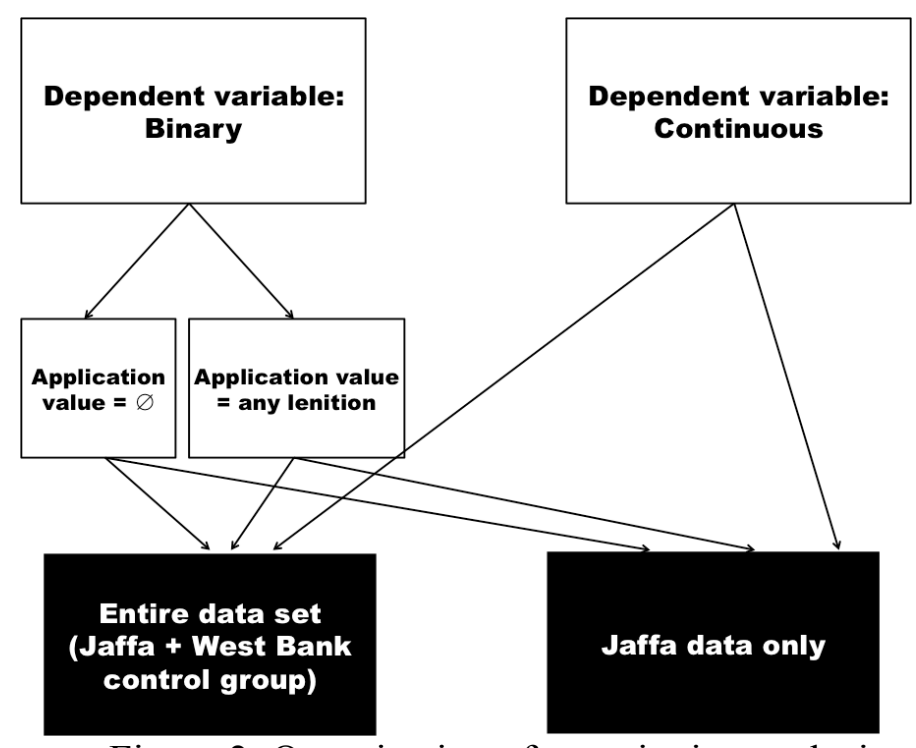

Figure 2: Organization of quantitative analysis

3. Envelope of variation. The variable (؟) was realized as and coded for five phonetic variants (the numbers below represent the numerical values given to the variants when the dependent variable was coded as a continuous variable):

0. $\varnothing$ (deletion), e.g., [bade:n] 'later' (traditionally baৎde:n)

1. ? (glottalization), e.g., [ba?de:n]

2. Compensatory lengthening, e.g., [ba:de:n]

3. Syllabic vocalization, e.g. [ba.a.de:n], [us.bu.a] 'week' (traditionally ?us.bu:S)

4. ؟ (traditional voiced pharyngeal fricative), e.g., [ba९de:n]

4. Summary of results. When isolating the Jaffa community and conducting a multivariate analysis of the data from that community alone using Rbrul (Johnson 2009), having recoded the dependent variable as a continuous one on a scale from 0 (total deletion) to 4 (full pharyngeal realization), the best models emerge with several social and linguistic factors contributing the most to the application of the variable rule. Most salient among the social factors appears to be language of schooling, whereby speakers who were schooled predominantly in Hebrew tend, unsurprisingly, to lenite their pharyngeals more than those educated in Arabic. The most salient 
linguistic factor (though this is yet to be refined) is position of the variable in the word; coda position prefers lenition over onset and consonant cluster.

Age group ( $<<0.001)$
\begin{tabular}{|l|l|l|}
\hline Factor & Log-odds & Tokens \\
\hline $36-60$ & 0.349 & 762 \\
\hline $14-35$ & 0.314 & 798 \\
\hline $61+$ & -0.662 & 332 \\
\hline
\end{tabular}

$\operatorname{Sex}(\mathrm{p}<0.0005)$

\begin{tabular}{|l|l|l|}
\hline Factor & Log-odds & Tokens \\
\hline Female & 0.233 & 923 \\
\hline Male & -0.233 & 969 \\
\hline
\end{tabular}

Occupational group $\left(\mathrm{p}<10^{-6}\right)$

Occupational group $\left(\mathrm{p}<10^{-6}\right)$
\begin{tabular}{|l|l|l|}
\hline Factor & Log-odds & Tokens \\
\hline Teenager & 0.562 & 336 \\
\hline Blue collar & 0.463 & 307 \\
\hline Service & -0.374 & 128 \\
\hline White collar & -0.651 & 1121 \\
\hline
\end{tabular}

$$
\mathbf{R}^{2}=\mathbf{0 . 3 0 4}
$$

$\mathrm{R}^{2}=0.304$

Table 1: Rbrul results for Jaffa \& West Bank (binary: deletion) 


\begin{tabular}{l}
\hline Occupational group $\left(\mathrm{p}<10^{-11}\right)$ \\
\begin{tabular}{|l|l|l|l|}
\hline Factor & Coefficient & Tokens & mean \\
\hline White collar & 0.285 & 1176 & 2.429 \\
\hline Service & 0.250 & 145 & 2.248 \\
\hline Blue collar & -0.067 & 580 & 2.697 \\
\hline Teenager & -0.468 & 601 & 2.300 \\
\hline
\end{tabular}
\end{tabular}

Language of primary/secondary schooling $\left(\mathrm{p}<10^{-22}\right)$

\begin{tabular}{|l|l|l|l|}
\hline Factor & Coefficient & Tokens & mean \\
\hline Arabic & 0.582 & 1618 & 2.621 \\
\hline Mixed & -0.092 & 450 & 2.378 \\
\hline Hebrew & -0.491 & 434 & 1.885 \\
\hline
\end{tabular}

Realization of pharyngeals in Hebrew speech $(\mathrm{p}<0.005)$

\begin{tabular}{|l|l|l|l|}
\hline Factor & Coefficient & Tokens & mean \\
\hline Pharyngeal & 0.200 & 476 & 2.668 \\
\hline Partial & -0.091 & 732 & 2.527 \\
\hline 0 & -0.109 & 1294 & 2.325 \\
\hline
\end{tabular}

Table 2: Rbrul results for Jaffa (continuous: all lenition variants)

\section{References}

Horesh, Uri. 2014. Phonological outcomes of language contact in the Palestinian Arabic dialect of Jaffa. Colchester: University of Essex PhD thesis. http://bit.ly/horeshphd. (4 July, 2014.)

Johnson, Daniel E. 2009. Getting off the GoldVarb standard: Introducing Rbrul for mixed-effects variable rule analysis. Language and Linguistics Compass 3:359-383.

http://danielezrajohnson.com/johnson_compass_final.pdf. (4 July, 2014.)

Thomason, Sarah G. and Terrence Kaufman. 1988. Language Contact, Creolization and Genetic Linguistics. Berkeley: University of California Press. 